\title{
Sobre el Momento de la Emancipación.
}

En ocasión distinta (I) fueron considerados los lapsos históricos del Perú: Períodos, Epocas, Sub-épocas y Momentos. En lo que sigue, trátase de enfocar el lapso histórico denominado Momento: tanto én su forma pura cuanto en su aplicación a la historia del Perú.

El Momento.-Considerando la totalidad de los lapsos históricos precedentes, distínguense dos grupos claramente diferenciables: uno, constituído por el Período, la Epoca y la Sub-épocá, yy caracterizado por mostrar una fisonomía estática; otro, constituido por el Momento, y caracterizado por mostrar una fisonomía dinamica.

Las partes de una totalidad histórica preséntanse, en función del primer grupo, como "eternamente" separadas, irremisiblemente paralíticas, dicho de otro modo: antihistóricas en su conjunto. Por esto se hace de urgencia considerar un componente nuevo, capaz de reconferirle su primitiva y viviente continuidad. Y esa estructura simple, capaz de devolver a lo que había sido dividido por motivos metodológicos-aunque nacidos de necesidades inherentes

(1) "Nuestra división histórica", por C. Valcárcel.-Revista "Letras", 3er. cuatrimestre.-Página 358. Lima 1941 (Nota.-Lo que en este artículo fué denominado "instante", actualmente lo hemos llamado "momento"; y lo que fué denominado "momento", actualmente lo hemos llamado "sub-época"). 
a la objetividad de lo histórico y a la subjetividad del Historiador-su unidad real, es el Momento. Cabe interrogarse entonces, acerca de los caracteres más generales que corresponden a dicho lapso.

Lo esencial del lapso 1lamado Momento, es esa su constante fugacidad, ese su perpetuo movimiento o substancial alteración. Muéstrase ante el observador como algo que no es por sí sino por otro, aquello que se consume para..., pues su sino es la transitoriedad. Por esto, cuando se le compara con los otros lapsos, en su papel categorial histórico, se nota-por contraste-cómo la importancia del Momento radica en aquella especialísima propiedad de permitir el "regreso" a la integridad indivisa de lo que había sido pasajeramente separado por el análisis, es decir de remostrar el fluyente devenir de lo histórico. De allí, que el Momento se presente relacionando o Períodos o Epocas o Períodos y Epocas-quizá también Sub-épocas. Hasta aquí, en la consideración teórica.

El Momento de nuestra Emancipación.-En la descripción genérico-empirica de la Historia del Perú nótase, como característica uhistoriograficar del Momento de la Emancipación-y también del Momento del Descubriiniento y de la Conquista-ser un lapso en donde el ritmo "normal" de los acontecimientos parece quebrarse. La viCa adquiere una prisa extraña, camínase aceleradamente en pos de (una meta idealizada). Un halo romántico acompaña inseparablemente al Momento, mientras los otros lapsos presentan la cadencia inconfundible de un burgués metódico. Pero ¿cuál es la razón suficiente de ser el Momento así y no de otra manera?. Permítaseme una contestación-con cargo de desdecirme.

Mientras en la materia histórica atañedera a los lap- 
sos de fisonomía estática (Período, Epoca, Sub-época) el Historiador aprehende, de manera inicial, lo que pertenece al espíritu objetivo en sentido estricto, es decir lo que pertenece a lo ya efectuado cuando se ha roto con el vínculo de origen, o sea cuando el acontecimiento tiene una realidad óntica por sí (independiente del Hombre, pero no de la Vida) y encuéntrase definitivamente sustantivado; en la materia histórica atañedera a los lapsos de fisonomía dinámica (Momentos), lo primero que aprehende el Historiador es el espíritu subjetivo (objetivado). Y solamente desde éste, pasa al espíritu objetivo propiamente dicho. Lo cual significa: que mientras allá el punto de partida-para la aprehensión-es el acontecer sustantivado; acá, el punto de partida-para-la aprehensión - es el acontecer en el "acontecedor", en el Hombre históricamente actuante o como se ha enunciado: en el espíritu subjetivo (objetivado). Esto lleva en último término hasta la afirmación que sigue: que la manera mejor de escudriñar lo interior del Momento empíricolhistórico, Ces partir de la Biografía. Lo dicho tiene legitimidad Dusospechada tercamente - para el Momento de nuestra Emancipación.

Cuando se contempla la gesta emancipadora del Perú, nótase cómo el espíritu se agita sacudido por un temblor emocional, que no logra producir, verbigracia, la época en que gobernaron los Virreyes. $Y$ esto hace más dificultosa la tarea de historiar - con validez objetiva. Lo apuntado nace del carácter peculiar de la materia histórica correspondiente al lapso llamado Momento. „Existen aquí situaciones de difícil calificación objetiva. La descripción y la explicación puramente racionales fracasan, pues la concatenación lógica se resiente con facilidad-ya que la pasión do- 
mina en los espíritus. Las objetivaciones históricas o acontecimientos esconden, con pudor superlativo, algo inalcanzable al escudriñador. Surge entonces la ineludible necesidad de aplicar el método de la Comprensión al estudiarlos- o no errar gracias a un certero instinto de Historiador. Dicho brevemente: en donde se hace más clara la eficacia del método de la Comprensión, más patente su utilidad para la ciencia de la Historia es, sobre todo, en este lapso (Momento). Y este comprender ha de realizarse en lo más cercano a la persona del Historiador: en el Hombre que actuó históricamente-como espíritu subjetivo (objetivado). Así mismo, servirá de auxiliar en el escudriñamiénto-aunque con cautela suma-la Psicología-cuidando de la caída en el "ismo" correspondiente. Solamente entonces, se llegará a la obtención del precipitado histórico más cercano a la verdad. El estudio de nuestro Momento de la Emancipación, tiende a ratificar los juicios precedentes.

Cuando los acontecimieintos de este Momento (Emancipación) son mirados desde la perspectiva del espiritu objetivo estricto, es cuando aparecen enunciados en donde existe un tácitogdistanciamiento comprensivo. En cambio, mirado este mismo lapso (Momento de la Emancipación) desde la perspectiva del espíritu subjetivo (objetivado), sortéanse los escollos y se hace presente la gentrina contribución histórica. Por ejemplo, lo esencial histórico de la oposición irreductible entre los partidarios y no partidarios de algunas figuras históricas de la Emancipación, nace (eliminando motivos segundos) del hecho que sigue: que el estudio histórico de dichos personajes ha sido efectuado "desde" el espíritu objetivo estricto, y no "desde" aquellos mismos Hombres, es decir partiendo del espíritu subjetivo (objetivado). El pecado de esta forma de historiar con- 
siste: en no haber contemplado, de manera inicial, a esos Hombres que lucharon por un ideal: la emancipación de las futuras repúblicas sudamericanas, en su grandeza y en su miseria propias, para luego "comprender" la aparente opacidad de ciertos actos. Y solamente después, pasar al escudriñamiento de los acontecimientos objetivamente válidos. En consecuencia: parece metodológicamente recomendable partir de la consideración biográfica, para poder adquirir un posterior y legítimo saber histórico del Momento.

Vertebralmente, la gesta emancipadora del Perú muestra la concatenación de tres figuras próceres: el chachapoyano Toribio Rodríguez de Mendoza, el limeño José Mariano de la Riva Agüiero, y el arequipeño Francisco Javier de Luna Pizarro (nótese el aporte del norte, del centro y del sur peruanos, es decir del Perú). Y la de una cuarta, y en cierta forma paralela: don Hipólito Unanue. (.Esto metodológicamente, QC sindolvidar a otros grandes peruanos como dōn fautistinon Sảnchez Garrión, por ejemplo).

Inicialmente estudiados como espíritu subjetivo (objetivado), podríase llegar hasta los acontecimientos propios de este lapso con menos psicologismo. Pues entonces habríamos comprendido los motivos profundos por los que esos Hombres actuaron así y no de otra manera. Esto se hace más necesario, en la Historia del Perú, sobre todo para comprender la figura de don José Mariano de la Riva Agüiero, en quien se acentúa, como en ninguna otra, la pasión y el esencial dramatismo de este lapso, denominado el Momento de la Emancipación.

Carlos Valcárcel. 